\title{
Short commentary on the population structure of Deepsea Shrimp, Aristeus alcocki from India.
}

\author{
Paramasivam Purushothaman* \\ Central Marine Fisheries Research Institute, Cochin - 682 018, Kerala, India \\ Centre of the ICAR-National Bureau of Fish Genetic Resources, CMFRI Campus, Cochin - 682 018, Kerala, India
}

Keywords: Aristeus alcocki, Shrimp production, Molluscs, Polychaetes.

Accepted on May 27, 2020

\section{Commentary}

According to FAO, shrimp production in India increased by $10 \%$ in 2018, due to the suitable climatic conditions and development of the fishery. Arabian red shrimp (Aristeus alcocki) is one of the important crustacean resources found in Indian seas. It has inhabited in the deep-sea regions and is widely distributed along the south-east and south-west coast of India with the depth of 200-3100 m. This shrimp is a highly perishable product in the export market, which has a shorter lifespan (6-7 years), compared to fishes, as a result, presence of high volume of free amino acids and other soluble nonnitrogenous substances. During earlier days, the landings of this shrimp was observed in more than ten major fishing harbours along the Indian coast, however in the later years, it is noticed only in Kerala and Tamil Nadu coasts. Conversely even now, more than $80 \%$ landings of this deep sea shrimp were observed from Sakthikulangara harbour of Kerala and there is no landing was noticed in Mumbai, Mangalore and Visakhapatnam coasts. The landing of recent years (2008 2017) were indicate that, the $A$. alcocki is the major species in order of biomass among the deep-sea penaeoid catch from the whole Indian coast. However trend in catch rates of the $A$. alcocki was showed declining phase during year of 2015-2016. The present study on "Investigation of genetic diversity and stock structure of Aristeus alcocki populations in the Indian coast" is providing baseline information, which is useful for the policy development and sustainable management of the resources in the future.

The genetic study [1] of Arabian red shrimp revealed that, no significant difference in populations along the Indian coast (Arabian and Bay of Bengal), which is probably attributed by the mixing of waters along the coastline, habitat, currents and migratory patterns of the species. However, it was found that, presence of significant variation in south-west population based on the variability in the abdominal characters, which might be presumed to the occurrences of food items in the benthic environment. Also, examined the $\operatorname{diet}$ of $A$. alcocki from the south-west coast and where the species feeds on a great variety of prey, its categories predominantly smaller crustaceans, for aminiferans, molluscs, polychaetes and bryozoans. Interestingly, it was observed that, females are effective predator than males which also has to be studied in detail in future. The genetic study [1] indicated the presence of high genetic diversity which forms a prerequisite for adaptive potential and selective responses. It was observed that, $A$. alcocki has synchronous development of oocyte and continuous breeding activity with high fecundity (average absolute fecundity of 131750 oocytes and relative fecundity of 7808 oocytes/g) [2-4]. The population dynamic characters (life span, size-frequency distribution, growth and mortality) signify that the species has remained stable during the study period (2013 to 2017) [5]. According to the fishery theory, the large population sizes and high fecundities tend to make $A$. alcocki scarcely susceptible to population damages.

The study on genetic survey $A$. alcocki was investigated with the uses of microsatellite markers based on the presences of their important features, which indicate optimal nuclear markers for population structure and genetic investigation purposes of this species. This shrimp is broadly distributed in the continental shelf and slope regions from the Gulf of Aden to Lakshadweep and Southwest coast of India to the Andaman Sea through the Bay of Bengal, but the present study is limited with the Indian coast. Future studies on this species should consider the whole geographical area to understand the extension of population structures (Figure 1).

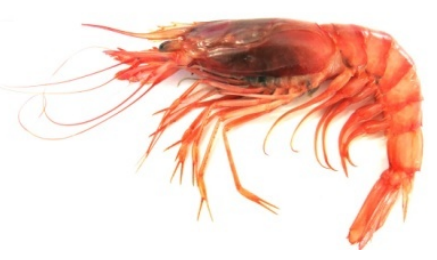

Figure 1. Structure of A. alcocki.

Continuous genetic monitoring is required, which help to promptly find out negative effects on genetic diversity of the species caused by fisheries and to provide data for developing sound management and conservation measures. If possible, closure of the fishing activity during peak breeding season of the species would allow increasing the population to the contribute to the next generation.

\section{Acknowledgements}

Author is expressing sincere thanks to Dr. Rekha Devi Chakraborty (Research Supervisor), Senior Scientist, Crustacean Fisheries Division and the Director, ICAR-Central Marine Fisheries Research Institute, Cochin-682018, Kerala, India for the facilities provided and encouragements during the Doctoral research. 
Citation: Purushothaman P. Short commentary on the population structure of Deepsea Shrimp, Aristeus alcocki from India. J Fish Res 2020;4(2):3-4.

\section{References}

1. Purushothaman P, Chakraborty RD, Kuberan G et al. Investigation of genetic diversity and stock structure of Aristeusalcocki Ramadan, 1938 (Decapoda: Aristeidae) populations in the Indian coast with microsatellite markers. Fisheries Research. 2020; 227: 1-7.

2. Purushothaman P. Integrative taxonomy of deep-sea shrimp Aristeusalcocki Ramadan, 1938 (Family: Aristeidae) resources along the Southern coast of India. Ph.D., Thesis, Mangalore University, 2018; 1-171.

3. Purushothaman P, Chakraborty RD, Kuberan G, et al. Stock structure analysis of 'Aristeusalcocki Ramadan, 1938 (Decapoda: Aristeidae)' in the Indian coast with truss network morphometrics. Canadian J Zool. 2018.

4. Purushothaman P, Chakraborty RD, Kuberan G, et al. Stock structure analysis of 'Aristeusalcocki Ramadan, 1938
(Decapoda: Aristeidae)' in the Indian coast with truss network morphometrics. Canadian J Zool. 2018.

5. Chakraborty RD, Purushothaman P, Maheswarudu G, et al. Populations dynamics of Aristeusalcocki Ramadan, 1938 (Decapoda: Penaeoidea: Aristeidae) from southwestern India. Reg Stud Mar Sci. 2018; 20: 64-71.

*Correspondence to

Purushothaman Paramasivam

Centre of the ICAR-National Bureau of Fish Genetic Resources,

\section{CMFRI Campus}

Kerala, India

E-mail: purushothgene@gmail.com 